\title{
CENSOS DE GANADO Y DE EXPLOTACIONES, DISTRIBUCIÓN DE LA POBLACIÓN Y USO DEL TERRITORIO EN LA PROVINCIA DE LEÓN: SITUACIÓN ACTUAL Y EVOLUCIÓN
}

\author{
E. SeRRANO; P. LAVÍn; A. R. MANTECón \\ Estación Agrícola Experimental del CSIC (León)
}

\section{INTRODUCCIÓN Y OBJETIVOS.}

Una característica física común al conjunto de la provincia de León es su elevada altitud, que supera, en cualquier punto de la provincia, los $200 \mathrm{~m}$. Se puede destacar que sólo el $3 \%$ de la superficie provincial se encuentra por debajo de los $600 \mathrm{~m}$ de altitud, que un $47 \%$ de la superficie de León se encuentra situada entre los 600 y $1000 \mathrm{~m}$ de altitud y que casi un $50 \%$ se sitúa por encima de la cota de los $1000 \mathrm{~m}$ (INE, 1990). La información recogida en la Tabla 1, relativa a algunas características del clima de la provincia de León, concuerda con estas características físicas, y con las clasificaciones realizadas por diversos autores (CABERO, 1987; MAYA, 1991b), en las que se define el clima de la provincia de León como de tipo continental, con contrastes violentos y rigores extremos, con largas etapas de heladas y con lluvias escasas y desigualmente distribuidas.

La situación descrita determina, en parte, que la actividad ganadera, y particularmente la derivada de la explotación de las tres principales especies de rumiantes domésticos (ganado bovino, ovino y caprino), haya jugado y juegue un papel esencial en la economía y en el modelado del medio natural de la provincia de León. Así, muchos valores ecológicos, culturales y paisajísticos son fruto de la acción sobre el medio de los sistemas ganaderos. La actividad ganadera es, también, la base de sostenimiento de un porcentaje muy importante de la población rural. Por ello, muchos de los procesos de deterioro social y medioambiental, que en la actualidad padece la provincia de León, pueden ser relacionados con cambios en los sistemas ganaderos o con su abandono.

El desarrollo de sistemas ganaderos sostenibles debe asentarse sobre el conocimiento de los sistemas ganaderos actuales. Las explotaciones son las unidades 
básicas de los sistemas ganaderos y son elementos complejos en los que se relacionan aspectos productivos, económicos, ambientales y sociales. Su estudio debe ser abordado teniendo en cuenta todos estos aspectos y también niveles distintos de detalle, considerando desde aspectos muy concretos de su funcionamiento hasta aspectos muy generales del entorno en el que desarrollan su actividad.

Tabla 1: Valores medios de altitud y pendiente y valores medios anuales de temperatura, meses de periodo cálido, meses de periodo frío y precipitación, para cada comarca de la provincia de León, en el periodo 1960-1996.

\begin{tabular}{lrrrrrrrr}
\hline & $(1)$ & $(2)$ & \multicolumn{4}{c}{ Temperatura ${ }^{\circ} \mathrm{C}$} & \multicolumn{3}{r}{ Periodo } & $(8)$ \\
\cline { 5 - 7 } & & & $(3)$ & $(4)$ & $(5)$ & $(6)$ & $(7)$ & \\
\hline Bierzo & 868 & 16,6 & 11,0 & 26,9 & $-0,5$ & 0,0 & 7,2 & 992 \\
M. Luna & 1.376 & 20,4 & 7,6 & 24,0 & $-3,5$ & 0,0 & 9,3 & 1061 \\
M. Riaño & 1.314 & 20,7 & 8,1 & 24,3 & $-3,3$ & 0,0 & 9,8 & 1198 \\
Cabrera & 1.251 & 20,1 & 8,3 & 24,4 & $-2,4$ & 0,0 & 8,0 & 846 \\
Astorga & 979 & 3,1 & 9,9 & 26,9 & $-2,1$ & 0,0 & 8,0 & 599 \\
T. León & 970 & 2,9 & 10,4 & 27,7 & $-2,0$ & 0,0 & 8,3 & 638 \\
Bañeza & 824 & 1,3 & 10,8 & 28,3 & $-1,4$ & 0,0 & 8,0 & 468 \\
Páramo & 804 & 0,8 & 11,0 & 28,8 & $-1,2$ & 0,2 & 8,5 & 450 \\
Esla-Campos & 797 & 0,9 & 11,8 & 30,1 & $-1,1$ & 1,1 & 8,0 & 462 \\
Sahagún & 860 & 0,9 & 11,6 & 29,5 & $-1,1$ & 0,7 & 8,0 & 501 \\
\hline
\end{tabular}

FuENTE: Sistema de Información Geográfica de Datos Agrarios (MAPA, 2002) ${ }^{1}$

(1) Altitud (m); (2) Pendiente (\%); (3) Temperatura media; (4) Temperatura media de las máximas del mes más cálido; (5) Temperatura media de las mínimas del mes más frío; (6) Periodo cálido: número de meses al año en que la temperatura media de las máximas es mayor de $30^{\circ} \mathrm{C}$; (7) Periodo frío: numero de meses al año en que la temperatura media de las mínimas es menor de $7^{\circ} \mathrm{C}$; (8) Precipitaciones (mm)

M. Riaño: Montaña de Riaño. M. Luna: Montaña de Luna. T. León: Tierras de León

Teniendo en cuenta los planteamientos anteriores, el objetivo de este trabajo es analizar la situación actual y la evolución reciente de los censos de ganado, de explotaciones, de población y del uso del territorio en la provincia de León. Como unidad de estudio para describir y comparar las distintas zonas de que se compone la provincia de León, se ha elegido la comarca. La división en comar-

\footnotetext{
${ }^{1}$ Los datos climáticos a nivel comarcal han sido elaborados por el Sistema de Información Geográfica de Datos Agrarios (MAPA, 2002), a partir de información procedente del Instituto Nacional de Meteorología, corresponden a 34 estaciones meteorológicas repartidas por las distintas comarcas de la Provincia de León y son el resultado de calcular la media de un periodo de 36 años, desde 1960 a 1996.
} 
cas se ha realizado tomando como referencia la utilizada por el Instituto Nacional de Estadística (INE, 1992), según la cual la provincia de León se compone de las 10 comarcas que a continuación se citan y cuya situación se representa en el Gráfico 1.

Gráfico 1: Las comarcas de León

Comarca I - Bierzo

Comarca II - La Montaña de Luna

Comarca III - La Montaña de Riaño

Comarca IV - La Cabrera

Comarca V - Astorga

Comarca VI - Tierras de León

Comarca VII - La Bañeza

Comarca VIII - El Páramo

Comarca IX - Esla-Campos

Comarca X - Sahagún

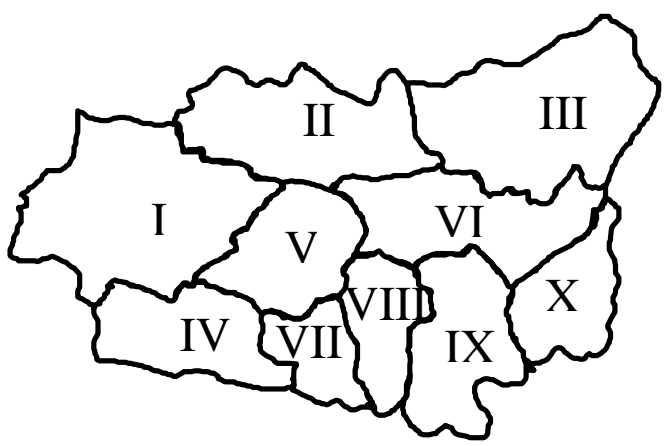

Tradicionalmente, el desarrollo de lo que conocemos como sistemas de producción animal se ha conseguido a través de la búsqueda del equilibrio, por medio de mecanismos complejos, entre las características del medio, los recursos que este ofrece y las necesidades de los animales. Como ya se indicó, la actividad ganadera también modela o modifica las características del medio en el que se desarrolla con consecuencias, positivas o negativas, sobre la calidad medioambiental del mismo y sobre la disponibilidad de recursos a largo y medio plazo (MONSERRAT, 1981; BALENT Y DURU, 1984; ABELLA ET AL., 1988; OWEN, 1994; HAVET ET AL., 1994; ZORITA, 1995; BALENT ET AL., 1998; D'HOUR ET AL., 1998). Esta íntima relación entre medio físico y sistemas ganaderos, implica la necesidad de avanzar un poco más, en esta introducción, en la descripción del medio físico de las comarcas que componen la provincia de León.

Como se puede apreciar en la Tabla 1, existen diferencias importantes en la altitud de las distintas comarcas que constituyen la provincia de León. Se puede decir, generalizando, que la altitud desciende a medida que avanzamos de norte a sur de la provincia. La comarca con mayor altitud media es Montaña de Luna, seguida muy de cerca de Montaña de Riaño. En estas dos comarcas, junto con la comarca de La Cabrera, la altitud media supera los $1000 \mathrm{~m}$. En el resto de las 
comarcas de la provincia la altitud media se sitúa entre los 750 y $1000 \mathrm{~m}$.

En el caso de los valores de pendiente media, los contrastes entre comarcas son aún más marcados que en el caso de la altitud. Destacan cuatro comarcas por los elevados valores de pendiente media. Estas comarcas, en las que los valores de pendiente media se sitúan entre el 20,7 y 16,6 \%, son, ordenadas de mayor a menor pendiente: Montaña de Riaño, Montaña de Luna, La Cabrera y el Bierzo. En la situación opuesta se encuentran las comarcas de El Páramo, Esla-Campos, Sahagún y La Bañeza, con unas pendientes medias comprendidas entre el $0,8 \%$ y el 1,3\%. En una situación intermedia, pero mucho más próxima a la del segundo grupo, se encuentran las comarcas de Astorga y Tierras de León, con pendientes del 2,9 y $3,1 \%$, respectivamente.

Dentro del panorama meteorológico descrito, dos comarcas, Montaña de Luna y Montaña de Riaño, destacan por presentar los valores más bajos de temperatura media, media de las mínimas y media de las máximas, el periodo frío de mayor duración y los valores más altos de precipitaciones medias anuales. En definitiva, se puede decir que en estas dos comarcas, a los rigores propios del clima leonés se suman los rigores propios de las zonas de montaña.

Exceptuando El Bierzo, en ninguna de las siete comarcas restantes la duración del periodo frío es inferior a 8 meses. De estas comarcas, las de La Cabrera, Astorga y Tierras de León presentan los valores más bajos de temperatura media, media de las máximas y media de las mínimas y los valores medios más altos de precipitaciones.

\section{DISTRIBUCIÓN DEL USO DEL TERRITORIO}

La provincia de León ocupa una superficie total de $15.580 \mathrm{~km}^{2}$ y, como se puede apreciar en las Tablas 2 y 3 , es un territorio muy heterogéneo en cuanto a la utilización del territorio. Los distintos usos del territorio se relacionan con las variaciones en la climatología y la altitud entre comarcas. Así, por ejemplo, las comarcas de mayor altitud, mayor precipitación y más montañosas, son las que presentan un mayor tamaño y en las que menor proporción de superficie está ocupada por tierras de cultivo (CABERO, 1987; MAYA, 1991B; MAYA Y PANIAGUA, 1993; LAVÍn, 1996).

Teniendo en cuenta la información recogida en la Tabla 2, relativa a la importancia relativa de las tierras de cultivo en las distintas comarcas, estas se pueden clasificar en tres grupos. El primero estaría compuesto por aquellas comarcas 
con un bajo porcentaje de tierras de cultivo: Montaña de Luna, Montaña de Riaño, La Cabrera y El Bierzo. El segundo agruparía a comarcas con un alto porcentaje de tierras de cultivo: Páramo, Esla-Campos y Sahagún. El tercero de estos grupos estaría constituido por aquellas comarcas que ocupan una situación intermedia respecto de los dos grupos anteriores: Astorga, Tierras de León y La Bañeza.

Tabla 2: Distribución del territorio ${ }^{2}$ en las comarcas de la provincia de León (ha y \% de la superficie total de la comarca) en el año 1999.

\begin{tabular}{crrrrrrrr}
\hline & \multicolumn{2}{c}{$\begin{array}{c}\text { Tierras de cul- } \\
\text { tivo }\end{array}$} & \multicolumn{3}{c}{$\begin{array}{c}\text { Prados y Pasti- } \\
\text { zales }\end{array}$} & \multicolumn{2}{c}{ Terreno Forestal } & \multicolumn{2}{c}{$\begin{array}{c}\text { Otras Superfi- } \\
\text { cies }\end{array}$} \\
\cline { 2 - 9 } & ha & $\%$ & ha & $\%$ & ha & $\%$ & ha & $\%$ \\
\hline I & 17.500 & 6,2 & 49.020 & 17,3 & 119.210 & 42,2 & 96.296 & 34,3 \\
II & 4.618 & 2,3 & 64.541 & 31,7 & 69.178 & 34,0 & 64.944 & 31,9 \\
III & 4.200 & 1,7 & 76.701 & 31,9 & 89.259 & 37,1 & 70.614 & 29,3 \\
IV & 6.075 & 4,8 & 23.167 & 18,1 & 70.684 & 55,3 & 27.839 & 21,8 \\
V & 24.200 & 17,3 & 24.577 & 17,6 & 55.430 & 39,7 & 35.565 & 25,4 \\
VI & 41.481 & 23,7 & 38.506 & 22,0 & 46.094 & 26,3 & 49.111 & 28,0 \\
VII & 24.756 & 37,9 & 6.958 & 10,6 & 15.978 & 24,4 & 17.693 & 27,1 \\
VIII & 58.912 & 65,0 & 7.535 & 8,3 & 2.514 & 2,8 & 21.612 & 23,9 \\
IX & 105.344 & 75,7 & 7.444 & 5,3 & 5.438 & 3,9 & 20.928 & 15,0 \\
X & 66.489 & 71,1 & 7.686 & 8,2 & 13.383 & 14,3 & 5.978 & 6,4 \\
\hline LEÓN & 353.575 & 22,7 & 306.135 & 19,6 & 487.168 & 31,3 & 411.210 & 26,4 \\
\hline
\end{tabular}

FUENTE: Elaboración propia a partir de información municipal proporcionada por el Servicio Territorial de Estadística de la Junta de Castilla y León.

I, Bierzo; II, Montaña de Luna; III, Montaña de Riaño; IV, Cabrera; V, Astorga; VI, Tierras de León; VII, Bañeza; VIII, Páramo; IX, Esla-Campos; X, Sahagún.

Considerando de nuevo la información recogida en la Tabla 2, se puede observar que de las cuatro comarcas agrupadas en el primero de los grupos citados (bajo \% de tierras de cultivo) dos, Montaña de Luna y Montaña de Riaño, presentan, tanto en términos absolutos como relativos, los valores más altos de su-

\footnotetext{
${ }^{2}$ Según la clasificación recogida en el Anuario Estadístico de Castilla y León, 2001 (JCyL, 2002):

Tierras de cultivo: superficies dedicadas a Cultivos herbáceos, a Barbechos y a Cultivos leñosos; Prados y Pastizales: superficies dedicadas a Prados o praderas permanentes y Otras superficies para pastos; Terreno forestal: superficies ocupadas por Monte maderable, Monte abierto y Monte leñoso; Otras superficies: terrenos clasificados como Erial a pastos, Espartizal, Terreno improductivo, Superficie no agrícola y Ríos y lagos.
} 
perficie dedicada a prados y pastizales y las otras dos, El Bierzo y La Cabrera, los valores más altos de superficie ocupada por terreno forestal. En la situación opuesta se encuentran las comarcas pertenecientes al segundo de los grupos establecidos (alto \% de tierras de cultivo). Estas comarcas (El Páramo, EslaCampos y Sahagún), presentan, como se puede ver en la Tabla 2, los valores más bajos de superficie dedicada a prados y pastizales y también a terreno forestal.

El territorio clasificado como otras superficies tiene la particularidad de no tener un uso agrícola ni ganadero, y por lo tanto, puede ser utilizado, sobre todo en algunas zonas, como un indicativo del grado de abandono en el uso del territorio. Teniendo en cuenta esta circunstancia, es interesante destacar el elevado porcentaje que supone este tipo de uso del territorio en el conjunto de la provincia $(26,4 \%)$ y en la mayoría de las comarcas. Sólo dos comarcas presentan bajos valores relativos de territorio clasificado como otras superficies: Esla-Campos $(15,0 \%)$ y Sahagún $(6,4 \%)$.

Las características generales del uso del territorio expuestas coinciden, en buena medida, con la clasificación de las comarcas de la provincia de León establecida por RODRÍGUEZ (1987). Este autor clasifica las comarcas de León, en función de su orientación técnico-económica, como: agrícolas, todas las comarcas de la Meseta (La Bañeza, El Páramo, Esla-Campos y Sahagún), aunque algunas de ellas cuenten con importantes efectivos ganaderos; como forestal, La Cabrera; como agrícola-ganadera, la de Tierras de León; como pastoralesganaderas-forestales, las de Montaña de Luna y Montaña de Riaño y como agrícola-ganadera-forestal, El Bierzo.

Las diferencias en el uso del territorio se asocian también, con frecuencia, a diferencias en el régimen de propiedad. Así por ejemplo, el régimen de propiedad comunal adquiere una especial importancia en las comarcas del norte de la provincia, en las que son mayores, también, los usos pastorales y forestales del territorio (MARÍN, 1993; MAYA ET AL., 1991A). Estas comarcas presentan una baja densidad de población, circunstancia que está, sin duda, relacionada con la menor disponibilidad de tierras aptas para el cultivo en estas zonas (CABERO, 1987; MAYA, ET AL., 1991A).

En línea con la reflexión anterior, LAVÍN (1996) encuentra una correlación positiva entre la extensión de los municipios de la provincia de León, la proporción de territorio ocupada por pastos, arbóreas y otras tierras y de signo negati- 
vo con la superficie catalogada como superficie agraria útil y tierras labradas. En el mismo estudio, la citada autora también encuentra una correlación, significativa y de signo positivo, entre las variables: extensión del municipio, altitud, precipitaciones, número de días de nieve, lluvia y granizo y temperatura mínima. En definitiva, las comarcas y los municipios de mayor altitud se corresponden, en términos generales, con los de mayor extensión, mayores precipitaciones, mayor número de días de lluvia, nieve y granizo y con los de mayor dedicación del territorio a pastos, prados naturales y usos forestales (MAYA ET AL., 1991A; LAVÍN, 1996).

Tabla 3: Distribución del territorio (\% del total provincial de cada tipo de superficie) en las comarcas de la provincia de León en el año 1999.

\begin{tabular}{crrrrr}
\hline & Total & \multicolumn{3}{c}{ \% del total de cada tipo de superficie en León } \\
\cline { 3 - 6 } & & $\begin{array}{r}\text { Tierras de } \\
\text { cultivo }\end{array}$ & $\begin{array}{r}\text { Prados y } \\
\text { Pastizales }\end{array}$ & $\begin{array}{r}\text { Terreno } \\
\text { Forestal }\end{array}$ & $\begin{array}{r}\text { Otras Su- } \\
\text { perficies }\end{array}$ \\
\hline I & 18,1 & 4,9 & 16,0 & 24,5 & 23,6 \\
II & 13,0 & 1,3 & 21,1 & 14,2 & 15,8 \\
III & 15,5 & 1,2 & 25,1 & 18,3 & 17,2 \\
IV & 8,2 & 1,7 & 7,6 & 14,5 & 6,8 \\
V & 9,0 & 6,8 & 8,0 & 11,4 & 8,6 \\
VI & 11,2 & 11,7 & 12,6 & 9,5 & 11,9 \\
VII & 4,2 & 7,0 & 2,3 & 3,3 & 4,3 \\
VIII & 5,8 & 16,7 & 2,5 & 0,5 & 5,3 \\
IX & 8,9 & 29,8 & 2,4 & 1,1 & 5,1 \\
X & 6,0 & 18,8 & 2,5 & 2,7 & 1,5 \\
\hline LEÓN & 100,0 & 100,0 & 100,0 & 100,0 & 100,0 \\
\hline
\end{tabular}

FUENTE: Elaboración propia a partir de información municipal proporcionada por el Servicio Territorial de Estadística de la Junta de Castilla y León.

I, Bierzo; II, Montaña de Luna; III, Montaña de Riaño; IV, Cabrera; V, Astorga; VI, Tierras de León; VII, Bañeza; VIII, Páramo; IX, Esla-Campos; X, Sahagún.

En la Tabla 4 se puede ver la evolución en el uso del territorio en el periodo 1990-1999. Considerando el total de la provincia, lo más destacado es el descenso en las tierras de cultivo $(18,2 \%)$ y el incremento del terreno forestal $(33,3 \%)$ y del catalogado como otras superficies $(18,3 \%)$. Considerando los valores relativos a la evolución del \% de territorio dedicado a tierras de cultivo de las comarcas consideradas individualmente, se puede destacar que sólo en una comarca, Sahagún, se produjo un incremento, muy moderado $(1,9 \%)$, de este ti- 
po de uso. En el resto de comarcas, por tanto, disminuyó el porcentaje de territorio dedicado a tierras de cultivo. En tres de ellas lo hizo moderadamente, El Bierzo, El Páramo y Esla-Campos, mientras que en las seis restantes, la disminución en el porcentaje de tierras de cultivo alcanzó valores relativos altos, comprendidos entre el 19,7\% de la comarca de Montaña de Riaño y el 53,6\% de La Cabrera.

Continuando con el análisis de la información recogida en la Tabla 4, se observa que la reducción, más menos generalizada, en el porcentaje de territorio ocupado por tierras de cultivo, se acompañó de distintos patrones de evolución en las distintas comarcas cuando nos referimos al porcentaje de superficie ocupado por prados y pastizales, terreno forestal u otras superficies. Para conseguir un análisis más sencillo de dicha evolución, siete de las comarcas estudiadas pueden clasificarse en tres grupos, constituidos: el primero, por las comarcas de Montaña de Riaño y Montaña de Luna; el segundo, por las comarcas de Astorga, Tierras de León y La Bañeza y el tercero, por las comarcas de El Páramo y Esla-Campos.

Tabla 4. Evolución ${ }^{3}$ en la distribución del territorio (\%) en las comarcas de la provincia de León en el periodo 1990-1999.

\begin{tabular}{|c|c|c|c|c|c|c|c|}
\hline & \multirow[t]{2}{*}{ (1) } & \multirow[t]{2}{*}{ (2) } & \multicolumn{4}{|c|}{ (3) Terreno Forestal } & \multirow[t]{2}{*}{ (4) } \\
\hline & & & (3a) & $(3 b)$ & $(3 c)$ & $(3 \mathrm{~d})$ & \\
\hline I & $-2,6$ & 1,0 & $-0,2$ & $-2,1$ & $-7,3$ & 6,6 & 1,0 \\
\hline II & $-34,4$ & 2,3 & 10,7 & 0,0 & 10,6 & 18,3 & 2,0 \\
\hline III & $-19,7$ & 2,4 & 3,1 & $-2,0$ & 4,4 & 7,8 & 0,0 \\
\hline IV & $-53,6$ & 14,0 & 0,2 & 0,1 & 0,1 & 0,3 & 17,3 \\
\hline $\mathrm{V}$ & $-46,0$ & 14,2 & 7,0 & 17,2 & 22,0 & $-3,4$ & 67,8 \\
\hline VI & $-34,1$ & 4,7 & 1,3 & 11,1 & $-7,5$ & 2,7 & 47,5 \\
\hline VII & $-28,0$ & 15,5 & 6,5 & 6,0 & 0,0 & 9,2 & 96,1 \\
\hline VIII & $-8,9$ & $-19,3$ & 25,4 & 241,2 & $-37,0$ & $-65,2$ & 49,6 \\
\hline IX & $-9,8$ & 11,6 & 27,7 & 118,7 & $-52,5$ & 0,0 & 92,4 \\
\hline $\mathrm{X}$ & 1,9 & $-6,7$ & $-4,8$ & $-13,1$ & 36,3 & $-13,8$ & 24,9 \\
\hline LEÓN & $-18,2$ & 3,6 & 33,3 & 3,2 & 1,9 & 4,3 & 18,3 \\
\hline
\end{tabular}

FUENTE: Elaboración propia a partir de información municipal proporcionada por el Servicio Territorial de Estadística de la Junta de Castilla y León. I, Bierzo; II, Montaña de Luna; III, Montaña de Riaño; IV, Cabrera; V, Astorga; VI, Tierras de León; VII, Bañeza; VIII, Páramo; IX, Esla-Campos; X, Sahagún. (1), Tierras de cultivo; (2), Prados y pastizales; (3), Terreno forestal; (3a), Total; (3b), Maderable; (3c), Abierto; (3d), Leñoso; (4), Otras superficies

\footnotetext{
${ }^{3} \%$ de variación calculado considerando $1990=100$.
} 
En las dos comarcas que componen la montaña de León, la pauta de evolución que acompañó a la disminución de las tierras de cultivo fue: un incremento moderado de las superficies dedicadas a prados y pastizales y a terreno forestal y un incremento moderado en la comarca de Montaña de Luna del \% de territorio catalogado como otras superficies (en la comarca de Montaña de Riaño la superficie dedicada a este tipo de uso permaneció estable). Es preciso señalar que, aunque porcentualmente las variaciones recogidas en la superficie dedicada a los usos citados (prados y pastizales, terreno forestal y otras superficies), no sean muy importantes, en términos absolutos lo son más, debido a la elevada importancia que estos usos tienen en estas dos comarcas. En la Tabla 4 se aprecia que el tipo de superficie que más se incrementó, dentro de las que constituyen el terreno forestal, tanto en la comarca de Montaña de Luna como en la de Montaña de Riaño, fue el monte leñoso.

En las comarcas de Astorga, Tierras de León y La Bañeza, las disminuciones, importantes, en el porcentaje de tierras de cultivo se acompañaron de incrementos, relativamente moderados, de la superficie dedicada a prados y pastizales y a terreno forestal y de incrementos, muy importantes, del territorio catalogado como otras superficies $(67,8 ; 47,5$ y $96,1 \%$, respectivamente).

En las comarcas de El Páramo y Esla-Campos, las disminuciones, moderadas, en el porcentaje de tierras de cultivo, se acompañaron de una disminución del terreno dedicado a prados y pastizales, en la primera, y de un incremento, en la segunda, y de incrementos importantes, en ambas comarcas, del territorio catalogado como terreno forestal y como otras superficies. Los incrementos de la superficie forestal en estas dos comarcas alcanzaron los valores relativos más altos de la provincia y son llamativos, teniendo en cuenta que ambas pueden catalogarse entre las comarcas de mayor carácter agrícola de la provincia. En la Tabla 4 se observa que el incremento de la superficie forestal se debió a incrementos, muy importantes en ambas comarcas, del terreno forestal clasificado como maderable. Esta información sugiere que el incremento de la superficie forestal, en estas dos comarcas, se debió a la dedicación de parte de las tierras que dejaron de tener usos agrícolas y ganaderos a cultivos de especies arbóreas para la producción de madera, principalmente chopos.

En la década de los 90 en la comarca de El Bierzo se mantuvieron más o menos estables las superficies dedicadas a cada uno de los usos considerados. No ocurrió así en La Cabrera, en la que la fuerte disminución de las tierras de cultivo (superior al 50\%) se tradujo en incrementos moderados del territorio clasifi- 
cado como prados y pastizales y otras superficies. Por último Sahagún, única comarca en la que en el periodo estudiado se incrementó la superficie dedicada a tierras de cultivo, se produjo un descenso de la superficie dedicada a prados y pastizales y del terreno forestal y un incremento del territorio clasificado como otras superficies.

La pauta de evolución comentada puede considerarse una continuación de la descrita por LAVÍN (1996) para el periodo (1982-1989). Aunque la información aportada por esta autora no es exactamente comparable a la recogida en este trabajo por las diferencias en las fuentes consideradas, sí se puede destacar que, en ese periodo: en todas las comarcas de la provincia de León se redujo la superficie agraria útil; que, excepto en las comarcas de Tierras de León y La Bañeza, en todas se incrementó el territorio catalogado como arbóreas y que, excepto en las comarcas de Montaña de Riaño y Sahagún, en todas se incrementó la superficie catalogada como otras tierras.

\section{CENSOS GANADEROS: SU DISTRIBUCIÓN Y EVOLUCIÓN}

En la Tabla 5 se recogen los censos de ganado vacuno, ovino y caprino de cada una de las comarcas que integran la provincia de León, los porcentajes que estos censos suponen respecto al censo provincial total de cada una de estas especies y su densidad (cabezas $/ \mathrm{km}^{2}$ ). En la Tabla 6 se recogen los valores relativos al número de explotaciones de ganado vacuno, ovino y caprino en cada una de las comarcas de León, el porcentaje que suponen respecto al censo provincial de explotaciones de cada especie y el número de explotaciones por $\mathrm{km}^{2}$.

De la información representada en las Tablas 5 y 6 se puede resaltar, en primer lugar, que, teniendo en cuenta el conjunto de la provincia, de las tres especies ganaderas consideradas, la que cuenta con una mayor importancia relativa, tanto por número de cabezas como por número de explotaciones, es el ganado vacuno, seguido del ovino y del caprino, por este orden.

En la Tabla 5 se puede apreciar que los censos de ganado vacuno, ovino y caprino de la provincia de León no se distribuyen de forma uniforme entre las distintas $\operatorname{com}^{\mathbf{o}}$ arcas que la componen. Dentro del conjunto provincial se pueden establecer dos grupos en función de la importancia del censo de ganado vacuno. Las comarcas que destacan por contar en términos relativos (cabezas $/ \mathrm{km}^{2}$ ) con un elevado censo de ganado vacuno son, de mayor a menor densidad: EslaCampos, Tierras de León, El Páramo, Montaña de Riaño y Montaña de Luna. 
En todas ellas la densidad media supera el valor medio provincial de 8,2 cabe$\mathrm{zas} / \mathrm{km}^{2}$.

Tabla 5: Censos $^{4}$ de ganado vacuno, ovino y caprino de las comarcas de León, en el año 2000.

\begin{tabular}{crrrrrrrrr}
\hline & \multicolumn{3}{c}{ Vacuno } & \multicolumn{3}{c}{ Ovino } & \multicolumn{3}{c}{ Caprino } \\
\cline { 2 - 9 } & $\mathrm{N}^{\mathbf{o}}$ & $\%$ & \multicolumn{1}{c}{ (a) } & $\mathrm{N}^{\mathrm{o}}$ & $\%$ & (a) & $\mathrm{N}^{\mathrm{o}}$ & $\%$ & (a) \\
\hline I & 8.035 & 6,3 & 2,9 & 39.544 & 6,8 & 14,1 & 5.511 & 15,5 & 2,0 \\
II & 18.535 & 14,5 & 9,0 & 31.488 & 5,4 & 15,3 & 6.750 & 18,9 & 3,3 \\
III & 24.584 & 19,3 & 10,2 & 31.757 & 5,4 & 13,2 & 7.829 & 22,0 & 3,3 \\
IV & 1.834 & 1,4 & 1,4 & 23.435 & 4,0 & 18,4 & 3.107 & 8,7 & 2,4 \\
V & 9.925 & 7,8 & 7,1 & 79.047 & 13,6 & 56,6 & 3.067 & 8,6 & 2,2 \\
VI & 22.744 & 17,8 & 12,8 & 75.807 & 13,0 & 43,2 & 3.644 & 10,2 & 2,1 \\
VII & 4.499 & 3,5 & 6,9 & 48.028 & 8,2 & 73,5 & 1.391 & 3,9 & 2,1 \\
VIII & 9.296 & 7,3 & 10,3 & 86.157 & 14,8 & 95,1 & 1.383 & 3,9 & 1,5 \\
IX & 21.291 & 16,7 & 15,3 & 126.190 & 21,6 & 90,5 & 2.427 & 6,8 & 1,7 \\
X & 6.706 & 5,3 & 7,2 & 41.764 & 7,2 & 44,8 & 532 & 1,5 & 0,6 \\
\hline LEÓN & 127.449 & 100,0 & 8,2 & 583.217 & 100,0 & 37,4 & 35.641 & 100,0 & 2,3 \\
\hline
\end{tabular}

FUENTE: Elaboración propia a partir de información municipal proporcionada por el Servicio Territorial de Estadística de la Junta de Castilla y León.

I, Bierzo; II, Montaña de Luna; III, Montaña de Riaño; IV, Cabrera; V, Astorga; VI, Tierras de León; VII, Bañeza; VIII, Páramo; IX, Esla-Campos; X, Sahagún.

(a), Cabezas $/ \mathrm{km}^{2}$

Considerando el número de explotaciones, la situación descrita en cuanto a distribución del censo de reproductoras varía. En este caso, podrían establecerse tres grupos de comarcas en función de la importancia relativa de las explotaciones de ganado vacuno (explotaciones $/ \mathrm{km}^{2}$ ). En el primer grupo se situarían aquellas comarcas que cuentan con una densidad de explotaciones de ganado vacuno superior a la media provincial $\left(0,44\right.$ explotaciones $\left./ \mathrm{km}^{2}\right)$. Estas comarcas, ordenadas de mayor a menor densidad, son: Tierras de León, La Bañeza, Esla-Campos, Astorga, El Bierzo y Montaña de Luna. En el segundo grupo, las comarcas de Montaña de Riaño y El Páramo presentan valores de densidad de explotaciones de ganado vacuno ligeramente inferiores a la media provincial. En el tercer grupo, Sahagún y La Cabrera presentan valores medios de explotaciones de ganado vacuno por $\mathrm{km}^{2}$ claramente inferiores a la media provincial,

${ }^{4}$ Ganado vacuno: censo de animales mayores de 6 semanas no destinados a cebo; Ganado ovino y caprino: censos de animales mayores de 6 meses. 
sobre todo en el segundo caso.

Tabla 6: Explotaciones de ganado vacuno, ovino y caprino de las comarcas de León, en el año 2000.

\begin{tabular}{|c|c|c|c|c|c|c|c|c|c|}
\hline & \multicolumn{3}{|c|}{ Vacuno } & \multicolumn{3}{|c|}{ Ovino } & \multicolumn{3}{|c|}{ Caprino } \\
\hline & $\mathrm{N}^{\mathrm{o}}$ & $\%$ & (a) & $\mathrm{N}^{\mathrm{o}}$ & $\%$ & (a) & $\mathrm{N}^{\mathrm{o}}$ & $\%$ & (a) \\
\hline I & 1.360 & 19,9 & 0,49 & 587 & 18,5 & 0,21 & 165 & 15,8 & 0,06 \\
\hline II & 965 & 14,1 & 0,47 & 327 & 10,3 & 0,16 & 191 & 18,3 & 0,09 \\
\hline III & 956 & 14,0 & 0,40 & 266 & 8,4 & 0,11 & 189 & 18,1 & 0,08 \\
\hline IV & 210 & 3,1 & 0,16 & 191 & 6,0 & 0,15 & 104 & 10,0 & 0,08 \\
\hline V & 696 & 10,2 & 0,50 & 265 & 8,3 & 0,19 & 96 & 9,2 & 0,07 \\
\hline VI & 923 & 13,5 & 0,53 & 389 & 12,2 & 0,22 & 112 & 10,7 & 0,06 \\
\hline VII & 339 & 5,0 & 0,52 & 165 & 5,2 & 0,25 & 53 & 5,1 & 0,08 \\
\hline VIII & 388 & 5,7 & 0,43 & 261 & 8,2 & 0,29 & 61 & 5,8 & 0,07 \\
\hline IX & 720 & 10,5 & 0,52 & 524 & 16,5 & 0,38 & 47 & 4,5 & 0,03 \\
\hline$X$ & 286 & 4,2 & 0,31 & 202 & 6,4 & 0,22 & 25 & 2,4 & 0,03 \\
\hline LEÓN & 6.843 & 100,0 & 0,44 & 3.177 & 100,0 & 0,20 & 1.043 & 100,0 & 0,07 \\
\hline
\end{tabular}

FUENTE: Elaboración propia a partir de información municipal proporcionada por el Servicio Territorial de Estadística de la Junta de Castilla y León.

I, Bierzo; II, Montaña de Luna; III, Montaña de Riaño; IV, Cabrera; V, Astorga; VI, Tierras de León; VII, Bañeza; VIII, Páramo; IX, Esla-Campos; X, Sahagún.

(a), Explotaciones $/ \mathrm{km}^{2}$

Según la importancia relativa de los censos de ganado ovino (cabezas $/ \mathrm{km}^{2}$ ), las comarcas de León pueden ser clasificadas en dos grupos en función de que superen o no el valor medio provincial. En el primer grupo se situarían, ordenadas de mayor a menor densidad, las comarcas de El Páramo, Esla-Campos, La Bañeza, Astorga, Sahagún y Tierras de León. En el segundo grupo se situarían, ordenadas también de forma decreciente según su densidad de ganado ovino, las comarcas de La Cabrera, Montaña de Luna, El Bierzo y Montaña de Riaño. Esta distribución es relativamente similar a la observada si consideramos el número de explotaciones. Así, las comarcas de Esla-Campos, El Páramo, La Bañeza, Tierras de León y El Bierzo, presentan valores superiores a la media provincial de densidad de explotaciones de ganado ovino y las comarcas de Astorga, Montaña de Luna, La Cabrera y Montaña de Riaño, inferiores.

Lo más destacado en relación con la situación del ganado caprino en la provincia de Léon es la baja importancia relativa tanto del censo de ganado como de explotaciones. El valor medio provincial de cabezas de ganado caprino por $\mathrm{km}^{2}$ equivale al 6,2\% del correspondiente al ovino. Los valores más altos de ca- 
bezas $/ \mathrm{km}^{2}$ corresponden a las comarcas de Montaña de Luna, Montaña de Riaño y La Cabrera y los más bajos a las comarcas de Sahagún, El Páramo y EslaCampos.

Conjugando la información de las Tablas 5 y 6, las comarcas de León se podrían clasificar, de forma muy general, en cinco grupos en función de su mayor o menor orientación ganadera y de la mayor o menor predominancia del ganado ovino o bovino.

En el centro y sur de la provincia se sitúan tres comarcas que cuentan con un fuerte desarrollo ganadero, tanto en lo que se refiere al ganado ovino como al vacuno. Estas comarcas son: Tierras de León, El Páramo y Esla Campos. La comarca de La Bañeza puede ser considerada dentro de este grupo, aunque se debe puntualizar que en ella el ganado ovino presenta una importancia relativa superior a la del ganado bovino.

El segundo grupo podría estar integrado por las dos comarcas que forman la Montaña de León, comarcas de Montaña de Luna y Montaña de Riaño. Estas dos comarcas se caracterizan por contar con un alto desarrollo ganadero centrado, fundamentalmente, en la explotación del ganado bovino. Respecto a la baja importancia relativa de los censos de animales y de explotaciones correspondientes al ganado ovino es preciso destacar que los datos recogidos en las Tablas 5 y 6 no incluyen los relativos al ganado trashumante. El censo de este tipo de ganado es relativamente importante en estas comarcas en las épocas de pastoreo estival.

Se puede considerar que las comarcas de Astorga y Sahagún ocupan una situación intermedia en cuanto a su desarrollo ganadero y se puede decir, también, que, en ambas, este está más dirigido hacia la explotación del ganado ovino.

La comarca de la Cabrera destaca por los bajos censos de animales y de explotaciones tanto de ganado ovino como de ganado bovino.

En el último grupo se encontraría la comarca de El Bierzo. Esta comarca se caracteriza por presentar censos relativamente bajos de ganado, tanto ovino como bovino, y censos relativamente altos de explotaciones. Esta circunstancia indica la predominancia, en esta comarca, de explotaciones de pequeño tamaño y que sirven de complemento a los ingresos obtenidos de otras actividades (agricultura, minería, etc). 
En la Tabla 7 se recoge la evolución de los censos de ganado vacuno, ovino y caprino, en las comarcas de la provincia de León, en los periodos 1982-1989 y 1989-2000.

En el primero de los citados periodos y considerando el conjunto de la provincia, el aspecto más destacado es el incremento en los censos de las tres especies consideradas. Este incremento no se distribuyó de forma uniforme en todas las comarcas que integran la provincia.

En lo que se refiere al ganado vacuno, todas las comarcas, salvo El Bierzo, incrementaron el número de cabezas. Los valores de incremento más altos correspondieron, en general, a comarcas situadas en el sur de la provincia y caracterizadas, en general, por un desarrollo importante de la agricultura, como El Páramo, La Bañeza, Esla-Campos, Sahagún y Astorga. En relación con esta observación, es preciso comentar, sin embargo, que, aunque en términos porcentuales respecto del censo comarcal de 1982, el incremento sea elevado, en términos absolutos, debido al bajo censo de ganado vacuno de estas comarcas, el incremento es más moderado. Este incremento del censo de ganado vacuno se produjo en una etapa previa al establecimiento de las cuotas lecheras y coincide con el desarrollo de un tipo de agricultura, ubicada en zonas de regadío, orientada a la producción forrajera.

Los censos de ganado ovino disminuyeron en la década de los ochenta en cuatro comarcas: Montaña de Riaño, Montaña de Luna y La Cabrera, que presentaron incrementos moderados de los censos de ganado vacuno, y en El Páramo, que presentó el incremento más importante, en términos relativos, del censo de ganado vacuno.

En el segundo periodo considerado (1989-2000), el análisis a nivel provincial revela un incremento ligero del censo de ganado vacuno, un incremento muy importante del censo de ganado ovino y un ligero descenso en el censo de ganado de la especie caprina. Sin embargo, como se puede ver en la Tabla 7, la evolución en las distintas comarcas no fue en absoluto homogénea, ni continuó, en muchos, casos la evolución registrada en la década anterior.

A diferencia de la etapa anterior, sólo cinco comarcas (Montaña de Luna, Montaña de Riaño, Tierras de Léon, Esla-Campos y Sahagún) incrementaron los censos de ganado vacuno. Esta circunstancia, se puede relacionar, de forma general, con el proceso de desaparición de ganado de aptitud lechera, y de explotaciones, que propició la instauración de las cuotas de producción de leche. 
Dentro del grupo de comarcas que incrementaron sus censos de ganado bovino, los incrementos más importantes correspondieron a las de Montaña de Luna y Montaña de Riaño, ambas con una orientación mucho más ganadera que agrícola y con una predominancia de recursos utilizables mediante el pastoreo. Por otro lado, se puede destacar que en tres de las cinco comarcas en que disminuyó el censo de ganado vacuno (Astorga, La Bañeza y El Páramo) se produjeron incrementos muy importantes de los censos de ganado ovino.

Tabla 7: Evolución ${ }^{5}$ (\%) en el censo de ganado vacuno, ovino y caprino, de las comarcas de León, en el periodo 1982-2000.

\begin{tabular}{crrrrrr}
\hline & \multicolumn{2}{c}{ Vacuno } & \multicolumn{2}{c}{ Ovino } & \multicolumn{2}{c}{ Caprino } \\
\cline { 2 - 7 } & $1982-1989$ & $1989-2000$ & $1982-1989$ & $1989-2000$ & $1982-1989$ & $1989-2000$ \\
\hline I & $-9,7$ & $-30,2$ & 54,2 & 43,5 & 17,6 & $-41,7$ \\
II & 1,7 & 25,4 & $-30,9$ & $-28,9$ & 54,4 & 53,7 \\
III & 7,5 & 49,8 & $-5,1$ & 45,2 & 6,3 & 26,0 \\
IV & 0,5 & $-37,5$ & $-18,5$ & 5,8 & $-23,7$ & $-55,5$ \\
V & 21,1 & $-6,6$ & 32,3 & 83,2 & 104,6 & 30,6 \\
VI & 7,3 & 6,0 & 45,5 & 1,9 & 6,0 & 38,7 \\
VII & 20,6 & $-30,1$ & 42,2 & 93,7 & 26,1 & 85,5 \\
VIII & 54,2 & $-27,8$ & $-7,4$ & 115,9 & 2570,5 & $-59,9$ \\
IX & 12,8 & 13,1 & 17,8 & 36,9 & 102,8 & 736,9 \\
X & 47,0 & 0,8 & 41,7 & $-9,2$ & 161,0 & 28,2 \\
\hline LEÓN & 12,2 & 4,0 & 12,7 & 33,7 & 20,9 & $-3,5$ \\
\hline
\end{tabular}

FUENTE: Elaboración propia a partir de información municipal proporcionada por el Servicio Territorial de Estadística de la Junta de Castilla y León.

I, Bierzo; II, Montaña de Luna; III, Montaña de Riaño; IV, Cabrera; V, Astorga; VI, Tierras de León; VII, Bañeza; VIII, Páramo; IX, Esla-Campos; X, Sahagún.

En relación con la evolución del número de cabezas de ganado caprino, es necesario tener en cuenta, que aunque porcentualmente se produjeron incrementos importantes en muchas comarcas, en términos absolutos no lo fueron tanto, debido al bajo censo que esta especie presentaba en la provincia de León. Aunque en conjunto se haya producido en las dos últimas décadas una cierta recuperación del censo de ganado caprino, los efectivos de este tipo de ganado continúan muy distantes de los valores alcanzados en otras épocas. Teniendo en cuenta la información recogida en la obra de Suárez et al. (1975), el censo de animales mayores de 1 año de la especie caprina se situaba en la provincia de León en el

\footnotetext{
${ }^{5} \%$ de variación calculado considerando 1982=100.
} 
año 1969 en torno a las 59.428 cabezas. Esto significa que el censo de animales mayores de 6 meses registrados en el año 2000 suponía sólo el $60 \%$ de censo de animales mayores de un año de 1969.

La consideración global de la información recogida en la Tabla 7 revela una tendencia, más o menos generalizada, hacia el incremento en los censos ganaderos en las dos últimas décadas. Esta tendencia general debe ser entendida, por un lado, en un proceso de reconversión de la agricultura hacia la producción de alimentos para el ganado, responsable del incremento de los censos ganaderos en las zonas más agrícolas de la provincia, y por otro, como el efecto de medidas políticas, entre las que destacan: la instauración de cuotas de producción de leche y las subvenciones al ganado bovino de carne y al ganado ovino y caprino.

La citada tendencia al incremento en los censos de ganado se ha acompañado, sin embargo, de importantes reducciones en el número de explotaciones. En la Tabla 8 se puede ver la evolución por comarcas del censo de explotaciones de ganado bovino, ovino y caprino entre los años 1989 y 2000.

En el caso del ganado vacuno, el número de explotaciones se redujo entre el año 1989 y el 2000 en todas las comarcas de León. En el conjunto de la provincia la reducción alcanzó casi el 65 \% de las explotaciones existentes en 1989. En el caso del ganado ovino, aunque a nivel provincial se registró un descenso importante en el número de explotaciones entre los años 1989 y 2000, en tres comarcas el número de explotaciones se incrementó (La Bañeza, El Páramo y Esla-Campos). Estas tres comarcas se cuentan, como ya se indicó, entre las de mayor carácter agrícola de la provincia y en todas se da la circunstancia de haber desarrollado una agricultura muy dirigida a la producción de alimentos para el ganado. Dicho ganado, que originariamente en zonas de regadío era mayoritariamente ganado vacuno, es ahora, como consecuencia de la aplicación de las cuotas lácteas, ganado ovino. Esta misma circunstancia se produce con el ganado caprino en las tres comarcas citadas y en la de Tierras de León.

Las consideraciones anteriores pueden ser precisadas si en el análisis de la evolución de los censos de ganado se tiene en cuenta la orientación productiva de los animales. En la Tabla 9 se recogen los censos de ganado vacuno de ordeño y de no ordeño en los años 1989 y 2000, en las comarcas que componen la provincia de León y la variación en porcentaje de los censos de estos dos tipos de ganado entre el año 1989 y el año 2000. 
Tabla 8: Evolución en el número de explotaciones de ganado vacuno, ovino y caprino de las comarcas de León, en el periodo 1989-20006.

\begin{tabular}{crrr}
\hline & Vacuno & Ovino & Caprino \\
\hline I & $-64,9$ & $-32,5$ & $-55,8$ \\
II & $-45,1$ & $-35,1$ & $-26,0$ \\
III & $-48,0$ & $-46,8$ & $-38,6$ \\
IV & $-74,4$ & $-62,8$ & $-74,2$ \\
V & $-70,1$ & $-22,1$ & $-2,0$ \\
VI & $-63,4$ & $-33,0$ & 12,0 \\
VII & $-77,7$ & 5,1 & 152,4 \\
VIII & $-77,0$ & 37,4 & 662,5 \\
IX & $-65,8$ & 13,7 & 27,0 \\
X & $-69,8$ & $-26,8$ & 0,0 \\
\hline LEÓN & $-64,7$ & $-27,7$ & $-36,1$ \\
\hline
\end{tabular}

FUENTE: Elaboración propia a partir de información municipal proporcionada por el Servicio Territorial de Estadística de la Junta de Castilla y León.

I, Bierzo; II, Montaña de Luna; III, Montaña de Riaño; IV, Cabrera; V, Astorga; VI, Tierras de León; VII, Bañeza; VIII, Páramo; IX, Esla-Campos; X, Sahagún.

A nivel provincial el censo de ganado de ordeño se redujo en un $32,9 \%$ y el censo de ganado de no ordeño se incrementó en un 880,9\%. Considerando los valores a nivel comarcal relativos a la evolución del censo de ganado de ordeño, destaca que sólo la comarca de Esla-Campos incrementó, ligeramente $(2,3 \%)$, el censo de este tipo de ganado. El resto de comarcas presentan reducciones, más o menos importantes, del censo de ganado de ordeño. Las reducciones más importantes correspondieron a las comarcas de El Bierzo (87,9\%), La Cabrera $(83,2 \%)$, Montaña de Luna (60,7 \%) y Montaña de Riaño (42,8 \%). Considerando los valores a nivel comarcal, relativos a la evolución del censo de ganado de no ordeño, es necesario destacar, en primer lugar, que en todas las comarcas se produjeron incrementos importantes en el censo de este tipo de ganado. Son especialmente destacables los incrementos registrados en las comarcas de Montaña de Riaño, Esla-Campos, Montaña de Luna y Astorga. En la comarca de Montaña de Riaño, el censo de este tipo de ganado de no ordeño pasó de las 275 cabezas a las 15.350 cabezas, lo que en porcentaje supone un incremento de casi el $5.500 \%$.

\footnotetext{
${ }^{6} \%$ de variación calculado considerando $1989=100$
} 
Tabla 9a: Censos de ganado vacuno de ordeño en el año 2000 y variación durante el periodo 1989-2000 en las comarcas de León.

\begin{tabular}{crrrrrr}
\hline & \multirow{2}{*}{2000} & \multirow{2}{*}{$\operatorname{Var}(\%)$} & \multicolumn{2}{c}{ \% comarca } & \% provincia \\
\cline { 4 - 7 } & & & 1989 & 2000 & 1989 & 2000 \\
\hline I & 1.225 & $-87,9$ & 88,0 & 15,2 & 8,6 & 1,6 \\
II & 5.671 & $-60,7$ & 97,5 & 30,6 & 12,3 & 7,2 \\
III & 9.234 & $-42,8$ & 98,3 & 37,6 & 13,7 & 11,7 \\
IV & 320 & $-83,2$ & 65,1 & 17,4 & 1,6 & 0,4 \\
V & 6.921 & $-34,0$ & 98,7 & 69,7 & 8,9 & 8,8 \\
VI & 18.188 & $-11,4$ & 95,6 & 80,0 & 17,4 & 23,0 \\
VII & 4.120 & $-35,2$ & 98,7 & 91,6 & 5,4 & 5,2 \\
VIII & 7.864 & $-35,8$ & 95,0 & 84,6 & 10,4 & 10,0 \\
IX & 19.214 & 2,3 & 99,8 & 90,2 & 16,0 & 24,3 \\
X & 6.187 & $-6,2$ & 99,2 & 92,3 & 5,6 & 7,8 \\
\hline LEÓN & 78.944 & $-32,9$ & \multicolumn{5}{c}{} \\
\hline
\end{tabular}

Tabla 9b: Censos de ganado vacuno de no ordeño en el año 2000 y variación durante el periodo 1989-2000 en las comarcas de León.

\begin{tabular}{crrrrrr}
\hline & \multirow{2}{*}{2000} & \multirow{2}{*}{$\operatorname{Var}(\%)$} & \multicolumn{2}{c}{ \% comarca } & \multicolumn{2}{c}{ \% provincia } \\
\cline { 4 - 7 } & & & 1989 & 2000 & 1989 & 2000 \\
\hline I & 6.810 & 394,6 & 12,0 & 84,8 & 27,8 & 14,0 \\
II & 12.864 & $3.376,8$ & 2,5 & 69,4 & 7,5 & 26,5 \\
III & 15.350 & $5.481,8$ & 1,7 & 62,4 & 5,6 & 31,6 \\
IV & 1.514 & 47,9 & 34,9 & 82,6 & 20,7 & 3,1 \\
V & 3.004 & $2.061,2$ & 1,3 & 30,3 & 2,8 & 6,2 \\
VI & 4.556 & 384,2 & 4,4 & 20,0 & 19,0 & 9,4 \\
VII & 379 & 356,6 & 1,3 & 8,4 & 1,7 & 0,8 \\
VIII & 1.432 & 123,4 & 5,0 & 15,4 & 13,0 & 3,0 \\
IX & 2.077 & $4.965,9$ & 0,2 & 9,8 & 0,8 & 4,3 \\
X & 519 & 861,1 & 0,8 & 7,7 & 1,1 & 1,1 \\
\hline LEÓN & 48.505 & 880,9 & & & & \\
\hline
\end{tabular}

FUENTE: Elaboración propia a partir de información municipal proporcionada por el Servicio Territorial de Estadística de la Junta de Castilla y León.

I, Bierzo; II, Montaña de Luna; III, Montaña de Riaño; IV, Cabrera; V, Astorga; VI, Tierras de León; VII, Bañeza; VIII, Páramo; IX, Esla-Campos; X, Sahagún.

${ }^{7}$ De acuerdo con la metodología utilizada en el Censo Ganadero General del Servicio de Estadística y Estructuras Agrarias de la Junta de Castilla y León los animales censados (mayores de 6 semanas no destinados a cebo) se clasificaron en dos categorías según su orientación productiva "ordeño" y "no ordeño". 
En la Tabla 9 se recogen los valores referidos a la importancia relativa a nivel comarcal y provincial de los censos ganado vacuno de ordeño y de no ordeño, en cada una de las comarcas que componen la provincia de León, en los años 1989 y 2000. Entre el año 1989 y el 2000, el censo provincial de ganado de ordeño pasó de suponer el 96,0 \% del censo total de ganado vacuno a suponer el $61,9 \%$. Esto implica que el censo de ganado de no ordeño pasó de suponer, en el citado periodo, el $4 \%$ del total provincial a suponer el $38,1 \%$.

En relación con el censo de cada comarca, en todas las comarcas de la provincia de León se produjo un incremento relativo de la importancia del censo de ganado de no ordeño frente al de ordeño, entre los años 1989 y 2000. La cuantía de estos incrementos varió, como se puede ver en la Tabla 9, de unas comarcas a otras. Los incrementos más marcados correspondieron a las comarcas de El Bierzo, Montaña de Luna, Montaña de Riaño, La Cabrera y Astorga.

Considerando la evolución seguida por los valores de importancia relativa del censo de ganado de ordeño de cada comarca en relación al total provincial (Tabla 9), se pueden establecer claramente dos grupos de comarcas: aquellas en las que el peso relativo del censo de ganado de ordeño en el conjunto provincial disminuyó (El Bierzo, Montaña de Luna, Montaña de Riaño y La Cabrera), y aquellas en las que la importancia relativa del censo de ganado de ordeño en el conjunto provincial aumentó (Tierras de León, Esla-Campos y Sahagún).

Como consecuencia del incremento provincial en el censo de ganado de no ordeño y de las diferencias entre comarcas en la cuantía del incremento de este tipo de ganado, sólo cuatro comarcas incrementaron la importancia relativa de su censo de ganado de no ordeño en el conjunto del total provincial. Estas comarcas son: Montaña de Riaño, cuyo censo de ganado de no ordeño pasó de suponer el 5,6 \% del total provincial a suponer el 31,6\%; Montaña de Luna, que pasó del 7,5 \% al 26,5 \%; Astorga, que pasó del 2,8 al 6,2 \% y Esla-Campos, que pasó de contar con el 0,8 \% del censo provincial de ganado de no ordeño a contar con el $4,3 \%$.

En dos comarcas, El Bierzo y La Cabrera, se redujo la importancia relativa, respecto al total provincial, tanto del censo de ganado vacuno de ordeño como de no ordeño.

La información anterior puede ser aún matizada considerando el censo de explotaciones y agrupando las explotaciones, según cuenten sólo con vacas de ordeño, sólo con vacas de no ordeño o con ambos tipos de ganado. Como se apre- 
cia en la Tabla 10, estos tres tipos de explotaciones tienen, a nivel provincial, una importancia relativa similar. De acuerdo con la información ya comentada, relativa a la distribución del censo de ganado de las explotaciones de ordeño, las explotaciones constituidas únicamente por vacas de ordeño son mayoritarias en las comarcas de Astorga, Tierras de León, La Bañeza, El Páramo, EslaCampos y Sahagún. Estas 6 comarcas agrupan más del 80 \% de las explotaciones constituidas sólo por vacas de ordeño de la provincia de León.

Tabla 10: Distribución, en función de la orientación productiva, de las explotaciones ${ }^{8}$ de ganado vacuno en las comarcas de la provincia de León, en el año 2000.

\begin{tabular}{crrrrrrrrr} 
& \multicolumn{3}{c}{ Sólo ordeño } & \multicolumn{3}{c}{ Sólo no ordeño } & \multicolumn{3}{c}{ Ordeño y no ordeño } \\
\cline { 2 - 9 } & $\mathrm{N}^{\circ}$ & $(\mathrm{a})$ & (b) & $\mathrm{N}^{\circ}$ & (a) & (b) & $\mathrm{N}^{\circ}$ & (a) & (b) \\
\hline I & 173 & 12,7 & 7,3 & 966 & 71,0 & 45,8 & 221 & 16,3 & 9,3 \\
II & 96 & 9,9 & 4,1 & 381 & 39,5 & 18,0 & 488 & 50,6 & 20,6 \\
III & 146 & 15,3 & 6,2 & 228 & 23,8 & 10,8 & 582 & 60,9 & 24,5 \\
IV & 49 & 23,3 & 2,1 & 124 & 59,0 & 5,9 & 37 & 17,6 & 1,6 \\
V & 309 & 44,4 & 13,1 & 150 & 21,6 & 7,1 & 237 & 34,1 & 10,0 \\
VI & 424 & 45,9 & 18,0 & 98 & 10,6 & 4,6 & 401 & 43,4 & 16,9 \\
VII & 233 & 68,7 & 9,9 & 37 & 10,9 & 1,8 & 69 & 20,4 & 2,9 \\
VIII & 271 & 69,8 & 11,5 & 50 & 12,9 & 2,4 & 67 & 17,3 & 2,8 \\
IX & 433 & 60,1 & 18,4 & 56 & 7,8 & 2,7 & 231 & 32,1 & 9,7 \\
X & 225 & 78,7 & 9,5 & 21 & 7,3 & 1,0 & 40 & 14,0 & 1,7 \\
\hline LEÓN & 2.359 & 34,5 & 100,0 & 2.111 & 30,8 & 100,0 & 2.373 & 34,7 & 100,0 \\
\hline
\end{tabular}

FUENTE: Elaboración propia a partir de información municipal proporcionada por el Servicio Territorial de Estadística de la Junta de Castilla y León.

I, Bierzo; II, Montaña de Luna; III, Montaña de Riaño; IV, Cabrera; V, Astorga; VI, Tierras de León; VII, Bañeza; VIII, Páramo; IX, Esla-Campos; X, Sahagún.

(a), \% comarca; (b), \% León.

Las comarcas de Astorga, Tierras de León y Esla-Campos, destacan también por que, aunque las explotaciones constituidas únicamente por vacas de ordeño son mayoritarias, las explotaciones con vacas de ordeño y no ordeño suponen un porcentaje importante $(34,1 ; 43,4$ y $32,1 \%$ del total, respectivamente). Esta

\footnotetext{
${ }^{8}$ De acuerdo con la metodología utilizada en el Censo Ganadero General del Servicio de Estadística y Estructuras Agrarias de la Junta de Castilla y León las explotaciones de ganado vacuno se clasificaron en tres categorías: "de ordeño", que son aquellas constituidas únicamente por vacas de ordeño; "de no ordeño", que son aquellas constituidas únicamente por vacas de no ordeño y "mixtas" que son aquellas en las que existen vacas de ordeño y de no ordeño.
} 
circunstancia puede ser entendida como una consecuencia del proceso de adaptación de muchas explotaciones a las limitaciones de cuota de producción de leche, en el que optan, cuando existe base territorial suficiente, por sumar al rebaño de reproductoras de ordeño un rebaño de reproductoras de no ordeño.

En el caso de las comarcas de Montaña de Riaño y Montaña de Luna, la mayoría de las explotaciones agrupan vacas de ordeño y de no ordeño (60,9 y 50,6 $\%$, respectivamente). Les siguen en cuantía las explotaciones que cuentan sólo con vacas de no ordeño ( 23,8 y $39,5 \%$, respectivamente) y el grupo menos numeroso lo constituyen las explotaciones formadas únicamente por vacas de ordeño (15,3 y 9,9\%, respectivamente). La comarca de Montaña de Riaño ocupa el primer lugar sobre el total provincial en número de explotaciones con vacas de ordeño y no ordeño $(24,5 \%$ del total provincial de este tipo de explotaciones). La comarca de Montaña de Luna ocupa el segundo puesto, con el 20,6 \% del total provincial de este tipo de explotaciones. La predominancia de este tipo de explotación en las zonas de montaña, puede explicarse siguiendo un razonamiento similar al expuesto anteriormente, relativo a las consecuencias del proceso de adaptación al sistema de cuotas lecheras.

Finalmente, en las comarcas de El Bierzo y La Cabrera el tipo de explotación dominante es el constituido únicamente por vacas de no ordeño.

Esta descripción general de las explotaciones de ganado vacuno de la provincia de León puede completarse con una referencia al tamaño de las explotaciones y a la evolución de este parámetro. En la Tabla 11 se recogen los valores medios de cabezas/explotación para el conjunto de explotaciones y para las explotaciones clasificadas en función del tipo de vacas que poseen (de ordeño, de no ordeño o ambas), para todas las comarcas de León, en el año 2000. En la Tabla 12 se recoge la evolución de los valores medios de cabezas/explotación para el total de explotaciones de ganado vacuno, sin considerar la orientación productiva de las reproductoras, para las 10 comarcas que forman la provincia de León, en el año 2000.

Considerando el total de explotaciones de la provincia, el número medio de cabezas/explotación fue de 18,6. Si consideramos a las explotaciones clasificadas en función de la orientación productiva de las reproductoras, el menor valor medio de cabezas/explotación correspondió a las explotaciones constituidas sólo por vacas de no ordeño (13,3 cabezas/explotación), el mayor a las explotaciones mixtas ( 21,8 cabezas/explotación) y ocuparon una posición intermedia 
las explotaciones constituidas sólo por vacas de ordeño $(20,1$ cabezas/explotación). El reducido número medio de cabezas/explotación de las explotaciones constituidas sólo por vacas de no ordeño, se debe, en parte, al reducido tamaño que estas explotaciones presentan en las comarcas de El Bierzo y La Bañeza, que cuentan de media con 6,2 y 5,1 cabezas/explotación, respectivamente.

Tabla 11: Tamaño medio ${ }^{9}$ (cabezas/explotación) de las explotaciones de ganado vacuno, consideradas globalmente y clasificadas en función de su orientación productiva ${ }^{10}$, en las comarcas de la provincia de León, en el año 2000.

\begin{tabular}{crrrr}
\hline & Global & Sólo ordeño & Sólo no ordeño & $\begin{array}{r}\text { Ordeño y } \\
\text { no ordeño }\end{array}$ \\
\hline I & 5,9 & 3,0 & 6,2 & 6,9 \\
II & 19,2 & 12,4 & 18,6 & 21,1 \\
III & 25,7 & 11,9 & 32,9 & 26,4 \\
IV & 8,7 & 4,2 & 11,0 & 7,1 \\
V & 14,3 & 15,1 & 12,5 & 14,2 \\
VI & 24,6 & 24,3 & 18,0 & 26,7 \\
VII & 13,3 & 13,3 & 5,1 & 17,5 \\
VIII & 24,0 & 23,6 & 24,0 & 25,5 \\
IX & 29,6 & 32,3 & 14,9 & 28,0 \\
X & 23,4 & 24,0 & 17,4 & 23,5 \\
\hline LEÓN & 18,6 & 20,1 & 13,3 & 21,8 \\
\hline
\end{tabular}

FUENTE: Elaboración propia a partir de información municipal proporcionada por el Servicio Territorial de Estadística de la Junta de Castilla y León.

I, Bierzo; II, Montaña de Luna; III, Montaña de Riaño; IV, Cabrera; V, Astorga; VI, Tierras de León; VII, Bañeza; VIII, Páramo; IX, Esla-Campos; X, Sahagún.

En cuanto a la evolución en el tamaño de las explotaciones, Tabla 12, el rasgo dominante, común a todas las comarcas y esperable, teniendo en cuenta la evolución del censo y del número de explotaciones, fue un marcado incremento en el número de cabezas por explotación. Este incremento fue, si consideramos el conjunto de la provincia, superior al $195 \%$.

En la Tabla 13 se puede ver la distribución del censo de ganado ovino de ordeño y de no ordeño, en el año 2000, en las comarcas que componen la provin-

\footnotetext{
${ }^{9}$ Tamaño medio de las explotaciones: obtenido como resultado de dividir el censo de animales mayores de 6 semanas no destinados a cebo entre el número de explotaciones.
} 
cia de León. Estos dos tipos de ganado no se distribuyen de forma homogénea en las comarcas de la provincia de León. Se pueden establecer cinco categorías de comarcas según la importancia relativa de cada uno. En la primera categoría estaría la comarca de Esla-Campos. En esta comarca, que agrupa el 49,1\% del censo de ovino de ordeño provincial, el ganado de ordeño supone el 90,8 \% del censo ovino total. La segunda categoría estaría constituida por las comarcas de El Páramo y Sahagún. En estas dos comarcas, los censos de ganado ovino de ordeño y de no ordeño están más equilibrados (50,7 vs 49,3 y 69,6 vs 30,4, respectivamente), aunque, en ambos casos, el ganado de ordeño supera al de no ordeño. En la tercera categoría se situarían las comarcas de Tierras de León y La Bañeza. En ambas, el ganado ovino de ordeño cuenta con una importancia relativa elevada, pero la del ganado ovino de no ordeño es claramente superior (27,4 vs 72,6 y 29,1 vs $70,9 \%$, respectivamente). En la última categoría se sitúan todas aquellas comarcas en las que la importancia relativa del censo ovino de ordeño es muy baja. Estas comarcas son El Bierzo, Montaña de Luna, Montaña de Riaño, La Cabrera y Astorga. En todas ellas la importancia relativa del censo de ganado ovino de ordeño es inferior al $10 \%$.

Tabla 12: Evolución del tamaño medio de las explotaciones ${ }^{12}$ (cabezas por explotación) de las explotaciones de ganado vacuno y ovino en las comarcas de la provincia de León, en el periodo1989-2000.

\begin{tabular}{|c|c|c|c|c|c|c|}
\hline & \multicolumn{3}{|c|}{ Ganado vacuno } & \multicolumn{3}{|c|}{ Ganado ovino } \\
\hline & 1989 & 2000 & $\%$ var & 1989 & 2000 & $\%$ var \\
\hline I & 3,0 & 5,9 & 96,9 & 31,7 & 67,4 & 112,7 \\
\hline II & 8,4 & 19,2 & 128,7 & 87,9 & 96,3 & 9,6 \\
\hline III & 8,9 & 25,7 & 188,9 & 43,7 & 119,4 & 173,0 \\
\hline IV & 3,6 & 8,7 & 142,6 & 43,2 & 122,7 & 184,1 \\
\hline $\mathrm{V}$ & 4,6 & 14,3 & 210,0 & 126,9 & 298,3 & 135,1 \\
\hline VI & 8,5 & 24,6 & 189,9 & 128,1 & 194,9 & 52,1 \\
\hline VII & 4,2 & 13,3 & 216,0 & 157,9 & 291,1 & 84,3 \\
\hline VIII & 7,6 & 24,0 & 215,2 & 210,1 & 330,1 & 57,1 \\
\hline IX & 8,9 & 29,6 & 232,3 & 200,0 & 240,8 & 20,4 \\
\hline $\mathrm{X}$ & 7,0 & 23,4 & 235,0 & 166,7 & 206,8 & 24,0 \\
\hline LEÓN & 6,3 & 18,6 & 195,6 & 99,4 & 183,6 & 84,8 \\
\hline
\end{tabular}

FUENTE: Elaboración propia a partir de información municipal proporcionada por el Servicio Territorial de Estadística de la Junta de Castilla y León.

I, Bierzo; II, Montaña de Luna; III, Montaña de Riaño; IV, Cabrera; V, Astorga; VI, Tierras de León; VII, Bañeza; VIII, Páramo; IX, Esla-Campos; X, Sahagún. 
Esta distribución del censo de ganado ovino de ordeño y no ordeño en las comarcas de la provincia de León coincide con la descrita por Lavín (1996) para el año 1991.

No fue posible disponer de información sobre los censos de ganado ovino de ordeño y no ordeño, equivalente a la disponible en el año 2000, para estudiar la evolución comarcal de los censos de estos dos tipos de ganado. La evolución de dichos censos sólo pudo ser analizada comparando los valores provinciales recogidos en los Anuarios de Estadística Agraria (MAPA, 1992, 2002). Según dichas fuentes de información, entre los años 1991 y 2001, en el conjunto de la provincia de León, el censo de ovejas que habían parido al menos una vez se incrementó en un 12,2\%. El número de efectivos de ordeño pasó, en dicho periodo, de 192.395 a 279.087 cabezas. Esto supone un incremento del 45,1\% en el censo de este tipo de ganado. El número de efectivos de no ordeño pasó de 316.242 a 291.401 cabezas. Esto supone una reducción del 7,9\% en el censo provincial de este tipo de ganado. Esta información concuerda con la expuesta en las Tablas 7 y 13, en las que se observa que en el periodo 1989-2000 se produjo un incremento del censo de ganado ovino y que, a nivel comarcal, este incremento afectó, fundamentalmente, a las comarcas del sur de la provincia, donde se concentra la mayoría del censo de ganado ovino de leche.

Tabla 13: Importancia relativa del ganado ovino de ordeño y de no ordeño en las comarcas de León, en el año 2000.

\begin{tabular}{crrrr}
\hline & \multicolumn{2}{c}{ Ganado ovino e ordeño } & \multicolumn{2}{c}{ Ganado ovino de no ordeño } \\
\cline { 2 - 5 } \% comarca & \% provincia & \% comarca & \% provincia \\
\hline I & 4,2 & 0,7 & 95,8 & 10,8 \\
II & 0,7 & 0,1 & 99,3 & 8,9 \\
III & 9,6 & 1,3 & 90,4 & 8,2 \\
IV & 1,1 & 0,1 & 98,9 & 6,6 \\
V & 8,0 & 2,7 & 92,0 & 20,8 \\
VI & 27,4 & 8,9 & 72,6 & 15,7 \\
VII & 29,1 & 6,0 & 70,9 & 9,7 \\
VIII & 50,7 & 18,7 & 49,3 & 12,1 \\
IX & 90,8 & 49,1 & 9,2 & 3,3 \\
X & 69,6 & 12,5 & 30,4 & 3,6 \\
\hline LEÓN & 40,0 & & 60,0 & \\
\hline
\end{tabular}

FUENTE: Elaboración propia a partir de información municipal proporcionada por el Servicio Territorial de Estadística de la Junta de Castilla y León.

I, Bierzo; II, Montaña de Luna; III, Montaña de Riaño; IV, Cabrera; V, Astorga; VI, Tierras de León; VII, Bañeza; VIII, Páramo; IX, Esla-Campos; X, Sahagún. 


\section{DISTRIBUCIÓN Y EVOLUCIÓN DE LA POBLACIÓN}

En el año 2001, la población total de la provincia de León era de 499.517 habitantes y la densidad media de 32,1 habitantes $/ \mathrm{km}^{2}$.

Como se aprecia en la Tabla 14, la población de la provincia de León se distribuye en las 10 comarcas que la forman de manera muy irregular. Si se establecen dos grupos de comarcas, discriminando entre aquellas que se sitúan por encima o por debajo de la densidad media provincial, vemos que sólo tres sobrepasan el valor medio provincial: El Bierzo, Tierras de León y La Bañeza.

Tabla 14: Distribución (habitantes) y densidad de población (habitantes $\left./ \mathrm{km}^{2}\right)^{10}$ de las comarcas de la provincia de León en el año 2001.

\begin{tabular}{crrrr}
\hline & $\begin{array}{r}\text { \% superficie } \\
\text { provincial }\end{array}$ & $\begin{array}{r}\mathrm{N}^{\circ} \text { de habitan- } \\
\text { tes }\end{array}$ & $\begin{array}{r}\text { \% habitantes } \\
\text { provincia }\end{array}$ & ${\text { Habitantes } / \mathrm{km}^{2}}^{2}$ \\
\hline I & 18,1 & 131.738 & 26,4 & 47,1 \\
II & 13,0 & 32.617 & 6,5 & 15,8 \\
III & 15,5 & 20.141 & 4,0 & 8,4 \\
IV & 8,2 & 5.455 & 1,1 & 4,3 \\
V & 9,0 & 35.771 & 7,2 & 25,6 \\
VI & 11,2 & 192.780 & 38,6 & 110,0 \\
VII & 4,2 & 24.256 & 4,9 & 37,1 \\
VIII & 5,8 & 21.757 & 4,4 & 24,0 \\
IX & 8,9 & 26.621 & 5,3 & 19,1 \\
X & 6,0 & 8.381 & 1,7 & 9,0 \\
\hline LEÓN & \multicolumn{5}{c}{} & 32,1 \\
\hline
\end{tabular}

FUENTE: Elaboración propia a partir de información municipal proporcionada por el Servicio Territorial de Estadística de la Junta de Castilla y León.

I, Bierzo; II, Montaña de Luna; III, Montaña de Riaño; IV, Cabrera; V, Astorga; VI, Tierras de León; VII, Bañeza; VIII, Páramo; IX, Esla-Campos; X, Sahagún.

La comarca que ocupa el primer puesto, tanto en censo total como en densidad de habitantes, es la comarca de Tierras de León. En esta comarca, que supone el 11,2\% de la superficie provincial y agrupa el 38,6\% de la población, se sitúa el núcleo más importante de población de la provincia que es, además, la capital. Los puestos segundo y tercero, en cuanto a densidad de población, co-

${ }^{10}$ Para el cálculo de la densidad de población de cada comarca, la extensión de cada una de ellas ha sido calculada a partir de los correspondientes valores municipales obtenidos del Nomenclator de 1986 de la provincia de Léon (INE, 1990). 
rresponden a las comarcas de El Bierzo y de La Bañeza, que agrupan el 26,4 y el 4,9\%, respectivamente, de los habitantes de la provincia. Las tres comarcas citadas (Tierras de León, El Bierzo y La Bañeza) agrupan el 69,9 \% de la población provincial y ocupan sólo el 33,4 \% de la superficie total de León.

El resto de comarcas se sitúan por debajo de la media provincial en cuanto a su densidad de población y en la mayoría de ellas el número de habitantes $/ \mathrm{km}^{2}$ se sitúa muy por debajo de la media provincial. Según se establece en la Directiva 75/268/CEE, las zonas en peligro de despoblación son aquellas que no sobrepasan una densidad de 37,5 habitantes $/ \mathrm{km}^{2}$. De acuerdo con esta cifra, todas las comarcas de León, salvo dos, pueden ser consideradas como territorios en peligro de despoblación. Los valores más bajos de densidad de población corresponden a las comarcas de La Cabrera $\left(4,3\right.$ habitantes $\left./ \mathrm{km}^{2}\right)$, Montaña de Riaño $\left(8,4\right.$ habitantes $\left./ \mathrm{km}^{2}\right)$ y Sahagún $\left(9\right.$ habitantes $\left./ \mathrm{km}^{2}\right)$.

Tabla 15: Evolución del número de habitantes y de la densidad de población (habitantes $/ \mathrm{km}^{2}$ ) en las comarcas de la provincia de León en los periodos 1981-1991 y 1991-200111.

\begin{tabular}{crrrrrr}
\hline & \multicolumn{3}{c}{$(1981-1991)$} & \multicolumn{3}{c}{$(1991-2001)$} \\
\cline { 2 - 7 } & habitantes & $\begin{array}{r}\text { Variación } \\
(\%)\end{array}$ & Habs/km ${ }^{2}$ & habitantes & $\begin{array}{r}\text { Variación } \\
(\%)\end{array}$ & Habs/km \\
\hline I & -2.158 & $-1,6$ & $-0,7$ & 60 & 0,0 & 0,0 \\
II & -3.360 & $-8,4$ & $-1,7$ & -4.107 & $-11,2$ & $-2,0$ \\
III & -5.284 & $-18,3$ & $-2,2$ & -3.401 & $-14,4$ & $-1,4$ \\
IV & -1.771 & $-23,0$ & $-1,4$ & -481 & $-8,1$ & $-0,4$ \\
V & -5.132 & $-11,9$ & $-3,6$ & -2.200 & $-5,8$ & $-1,6$ \\
VI & 23.920 & 14,1 & 13,7 & -1.211 & $-0,6$ & $-0,7$ \\
VII & -1.940 & $-7,1$ & $-3,0$ & -1.216 & $-4,8$ & $-1,9$ \\
VIII & -3.718 & $-13,6$ & $-4,1$ & -1.875 & $-7,9$ & $-2,1$ \\
IX & -4.738 & $-14,4$ & $-3,4$ & -1.435 & $-5,1$ & $-1,0$ \\
X & -2.315 & $-20,1$ & $-2,5$ & -739 & $-8,6$ & $-0,9$ \\
\hline LEÓN & -6.496 & $-1,2$ & $-0,4$ & -16.659 & $-3,2$ & $-1,1$ \\
\hline
\end{tabular}

FUENTE: Elaboración propia a partir de información municipal proporcionada por el Servicio Territorial de Estadística de la Junta de Castilla y León.

I, Bierzo; II, Montaña de Luna; III, Montaña de Riaño; IV, Cabrera; V, Astorga; VI, Tierras de León; VII, Bañeza; VIII, Páramo; IX, Esla-Campos; X, Sahagún.

En la Tabla 15 se recoge la evolución de la población en la provincia de León

${ }^{11} \%$ de variación calculados considerando 1981=100 y 1991=100, respectivamente. 
en los periodos 1981-1991 y 1991-2001. La población de la provincia de León alcanzó su máximo valor en 1960 con 584.594 habitantes. A partir de esta fecha, las pautas generales de evolución son el descenso global en la población de la provincia y el incremento en la población de la capital. La densidad de población en la provincia de León disminuyó en 0,4 y 1,1 habitantes $/ \mathrm{km}^{2}$ en los periodos 1981-1991 y 1991-2001, respectivamente. Además, todas las comarcas, salvo la de Tierras de León, perdieron población en la década de los 80. En la década siguiente, periodo 1991-2001, la tendencia general de pérdida de población se incrementó y afectó, incluso, a la comarca de Tierras de León, en la que, como ya se comentó, se sitúa la capital de la provincia.

Otro aspecto importante relativo a la evolución de la población en la provincia de León en las últimas dos décadas, es la reducción drástica de la población activa dedicada a la agricultura. Así, mientras en 1981 el 41,2 \% de la población activa era catalogada como activa agrícola, en 1991 este porcentaje se redujo hasta el 19,3\% y hasta el 10,4\% en el año 2001 (INE, 2002).

\section{CONCLUSIONES}

Como ya se indicó al inicio de este trabajo la actividad ganadera juega, en general, un papel esencial en la gestión del territorio. Esta afirmación es, si cabe, aún más cierta en la provincia de León como consecuencia de sus características físicas y climatológicas. Un factor de gran importancia en la evolución reciente de los sistemas ganaderos es la Política Agraria Comunitaria. A través de dicha política se han invertido grandes esfuerzos económicos en el desarrollo de sistemas ganaderos sostenibles.

En las dos últimas décadas se han incrementado los censos provinciales de las dos principales especies de rumiantes domésticos explotadas en León: el ganado vacuno y el ovino. Paralelamente a este incremento en los censos de ganado vacuno y ovino, se ha producido una fuerte disminución en el número de explotaciones de ambas especies. En el caso del ganado vacuno, esta disminución ha afectado a todas las comarcas de León. En el caso del ganado ovino, el número de explotaciones disminuyó en 7 de las 10 comarcas que componen la provincia. El análisis de la evolución en el uso del territorio y de la población, muestran procesos crecientes de abandono del territorio y de despoblación.

Entre otros aspectos, la situación descrita puede considerarse indicativa de un desarrollo ganadero alejado o desvinculado del uso de los recursos naturales. 
Esta situación es fruto de tres patrones de evolución seguidos mayoritariamente por las explotaciones, condicionadas por la situación socioeconómica actual (ORTUÑO Y FERNÁNDEZ-CAVADA, 1995; ALBERDI, 2001; SERRANO ET AL., 2002): intensificación, extensificación y marginalización.

Los dos primeros patrones de evolución corresponden a explotaciones que han decidido continuar con la actividad ganadera. En ambos casos se ha producido una desvinculación de la utilización de los recursos naturales.

El proceso de intensificación ha dado lugar a sistemas ganaderos centrados en las zonas agrícolamente más productivas y muy dependientes de aportes externos de materias primas. Este proceso ha afectado más a las comarcas con mayor carácter agrícola. El abandono de las zonas más marginales, menos productivas, ha hecho que la actividad de explotación de rumiantes haya perdido en estas áreas su función de aprovechamiento y valorización de recursos marginales, no utilizables de otra forma (ZORITA, 1995, ALBERDI, 2001).

El proceso de extensificación ha dado lugar a sistemas desvinculados de la utilización del territorio por la subutilización que hacen de este. Estos sistemas, orientados, fundamentalmente, hacia la producción de carne, permiten manejar un elevado número de cabezas de ganado por unidad de mano de obra y la baja productividad individual por animal se compensa incrementando el número de cabezas manejadas por trabajador, lo que permite, además, maximizar los ingresos por subvenciones. La Política Agraria Comunitaria ha favorecido el desarrollo de este tipo de sistemas de producción. La aplicación de la política de subvenciones, de las cuotas de producción de leche y de la normativa sobre higiene y calidad de la leche, han sido factores decisivos en el desarrollo de este tipo de sistemas, favoreciendo el incremento de los censos de ganado vacuno de carne y la disminución de los de leche (ORTUÑO Y FERNÁNDEZ-CAVADA, 1995; SERRANO ET AL., 2002).

El tercer patrón, marginalización, es el seguido mayoritariamente por las explotaciones que avanzan hacia el abandono de la actividad. Los rasgos más característicos de estas explotaciones son el abandono de la actividad productiva más exigente en mano de obra e instalaciones, generalmente la leche, y el estancamiento o disminución en el censo de animales de la explotación (ALBERDI, 2001).

Como conclusión final, se podría resaltar que la información expuesta en este trabajo pone en duda la efectividad, de muchas de las políticas agrarias, sociales 
y medioambientales llevadas a cabo en las dos últimas décadas, entre ellas la Política Agraria Comunitaria, como instrumentos para mantener un nivel adecuado de población y de actividad agraria en el medio rural de la provincia de León que permitan conservar y gestionar adecuadamente un territorio muy humanizado.

\section{BIBLIOGRAFÍA}

Abella, M. A.; Fillat, F.; Gómez, A.; Lasanta, T.; Manrique, E.; MÉNDEZ, C.; REVILLA, R. Y RUIZ, M. (1988). «Sistemas ganaderos de montaña». Agricultura y Sociedad, 46: 119-179.

ALBERDI, J. C. (2001). «De leche hacia carne: hacia el abandono de la actividad ganadera». Estudios Agrosociales y Pesqueros, 193: 57-86.

BALENT, G. ET DURU, M. (1984). «Influence des modes d'exploitation sur les caractéristiques et l'évolution des surfaces pastorales: cas de Pyrénées Centrales». Agronomie, 4: 113-124.

BALENT, G.; AlARD, D.; BLANFORT, V. Y GIBON, A. (1998). «Activités de pâturage, paysages et biodiversité». Producción ovina y caprina, XXIII: 1930.

CABERO, V. (1987). «El espacio geográfico y el soporte físico de la Comunidad Autónoma de Castilla y León». En: La integración de España en la CEE y el sector agrario de Castilla y Léon. pp. 43-78. Asociación CastellanoLeonesa de Ciencia Regional. Salamanca (España).

D'HOUR, P.; REVILLA, R. AND WRIGT, I. A. (1998). «Possible adjustments of suckler herd management to extensive situations». Productions Animales, 11: 379-386.

Havet, A.; Gibon, A.; Hubert, B. et RouX, M. (1994). «Méthodologie d'étude des relations élevage-environnement. Quatre exemples de recherche pour l'action en France». En: The study of livestock farming systems in a research and development framework. (Gibon, A.; Flamant, J. C., eds.). pp. 101-105. Wageningen Pers. Wageningen (Holland).

INE (1990). Nomenclator, 1986, León. Instituto Nacional de Estadística. Madrid (España).

INE (1992). Relación de municipios y códigos de provincias 1991. Instituto Nacional de Estadística. Madrid (España).

INE (2002). «Encuesta de Población Activa». En: INEbase, Sociedad. Página WWW. http://www.ine.es/inebase/cgi/um. 1 de marzo de 2002. 
LAVÍN, M. P. (1996). Los sistemas de producción ovina de la provincia de León: factores condicionantes de su distribución y estructura. Tesis Doctoral. Universidad de León. León (España).

MapA (1992). Anuario de Estadística Agraria 1991. Ministerio de Agricultura, Pesca y Alimentación. Madrid (España).

MapA (2002). Anuario de Estadística Agraria 2001. Ministerio de Agricultura, Pesca y Alimentación. Madrid (España).

MARÍN, A. (1993). El mercado de la tierra agraria: estudio de la provincia de León. Universidad de León. León (España).

MAYA, A. (1991a). «Cambios en la estructura agraria de León en la última década». Polígonos, 1: 95-114.

MAYA, A. (1991b). «La diversidad geográfica de la provincia de León. Tradición y modernización agrarias en un modelo de agricultura sostenible». Phytomas, 8: 52-58.

MAYA, A. Y PANIAGUA, A. (1993). «Alcance y desarrollo de las políticas de retirada de tierras y de jubilación anticipada en el ámbito de Castilla y León: implicaciones espaciales y efectos socioestructurales». En: El mundo rural en la encrucijada: repercusiones territoriales de la PAC. (Maya, A.; Paniagua, A.; Bello, A., eds.). pp. 71-98. Excma. Diputación Provincial de León. León (España).

MonSERRAT, P. (1981). «Ecología de pastos y fomento agropecuario en la montaña». Pastos, 11: 5-13.

ORTUÑO Y FERNÁNDEZ-CAVADA, J. L. (1995). «Perspectivas económicas de las producciones ganaderas extensivas en las áreas desfavorecidas ante la liberalización de los mercados». Revista de Estudios Agro-Sociales, 164:93111.

OWEN, J. B. (1994). «Pollution in livestock production systems-an overview». In: Pollution in Livestock Production Systems. (Dewi, I. A.; Axford, R. F. E.; Fayez, I.; Marai, M.; Omed, H. M., eds.) pp. 1-15. CAB International. Wallingford (United Kingdom).

SERRANO, E.; LAVÍN, P.; MANTECÓN, A.R. (2002). Caracterización de los sistemas de producción de ganado vacuno de carne de la montaña de León. (Ed: Valles del Esla S.A.). León (España).

SuÁrez, A.; MAntero, M. C.; Revuelta, J. F. Y PuEnTE, T. (1975). La ganadería leonesa y sus posibilidades de desarrollo. Fundación Fray Bernardino de Sahagún. León (España).

ZORITA, E. (1995). «Los sistemas pastorales y la conservación de la naturaleza 
en la España peninsular. Una perspectiva histórica». En: Sistemas extensivos de producción de rumiantes en zonas de montaña. (Revuelta, J.F.; Cañon, J., eds.). pp. 13-39. Consejo General de Colegios Veterinarios de España. Madrid (España).

\section{RESUMEN}

En este trabajo se estudia la distribución actual y la evolución, en las dos últimas décadas, del uso del territorio, de los censos de ganado y explotaciones y de la población, en las diez comarcas que componen la provincia de León. La evolución reciente del uso del territorio revela una disminución en las tierras de cultivo y un incremento del territorio catalogado como otras superficies. En las dos últimas décadas se han incrementado los censos de ganado y ha disminuido el número de explotaciones. En la evolución de los censos ganaderos, ha sido especialmente llamativa la disminución en el censo de ganado vacuno de leche y el incremento en el censo de ganado vacuno de carne. En la década de los 80, la población disminuyó en todas las comarcas de la provincia de León, salvo en la de Tierras de León. En la década de los 90, la pérdida de población afectó incluso a esta comarca.

Palabras clave: ganadería, uso del territorio, población, provincia del León.

\section{ABSTRACT}

The aim of this paper is made up an overviw about distribution and evolution of land use, livestock census and population in the province of León. The study of recent evolution of land use shows a drop in the area of arable lands and an increase in the area of others lands. During the two last decades, livestock census has increased and farm number has dropped. With regard to livestock census evolution, it has been specially important the drop in dairy cattle census and the increase in beef cattle census. In the eighties, population dropped in all León areas, except Tierras de León. In the nineties, population drop even affected that area.

Keywords: livestock, land use, population, province of León.

\section{RÉSUMÉ}

L'objectif de ce travail est etudier la distribution et l'évolution de l'utilisation du territoure, des recensements du bétail et de la population pendant les derniers 20 années à la province de León.

L'évolution récente de l'utilisation du territoure se caractérise par une baisse des terres de culture et par une augmentation des terres classés comme outres terres. Pendant les derniers 20 années les recensements de bétail ont augmenté et les recensements de exploitations ont baissé. En ce qui concerne évolucion des recensements de bétalil il y a été très importante la baisse des recensements de bovins laitiers et l'augmentation des recensements de bovins de viande. En la déccennie 1980-1990, la population a disminué en toutes les régions de la province de León sauf Tierras de León. En la déccennie 1990-2000 la population a disminié en toutes les régions de la province de León.

Mots clés: élevage, utilisation du territoure, population, province de León. 